\title{
Some Technical Solutions for Environmental Protection System during Accidents at Nuclear Power Plants
}

\author{
Sergey A. Kulyukhin ${ }^{1}$, Igor' A. Rumer ${ }^{1}$, Viktor M. Berkovich², Gennadii S. Taranov', \\ Ivan V. Yagodkin ${ }^{3}$, Viktor P. Osipov ${ }^{3}$, Sergey S. Skvortsov³, Leo N. Falkovskii ${ }^{4}$ \\ ${ }^{1}$ Frumkin' Institute of Physical Chemistry and Electrochemistry, Russian Academy of Sciences (IPCE RAS), Moscow, Russia \\ ${ }^{2}$ Institute “Atomenergoproekt" (AEP), Moscow, Russia \\ ${ }^{3}$ Institute of Physics and Power Engineering (IPPE), Obninsk, Russia \\ ${ }^{4}$ All-Russian Research Institute of Atomic Machine-Building (VNIIAM), Moscow, Russia \\ Email: kulyukhin@ipc.rssi.ru
}

How to cite this paper: Kulyukhin, S.A. Rumer, I.A., Berkovich, V.M., Taranov, G.S., Yagodkin, I.V., Osipov, V.P., Skvortsov, S.S. and Falkovskii, L.N. (2017) Some Technical Solutions for Environmental Protection System during Accidents at Nuclear Power Plants. World Journal of Engineering and Technology, 5, 1-11.

https://doi.org/10.4236/wjet.2017.54B001

Received: April 12, 2017

Accepted: October 9, 2017

Published: October 12, 2017

\begin{abstract}
The paper reports some technical solutions, which suggested or used for increasing of environmental protection during accidents at NPPs. For NNPs with two protective shells and pressure release system such as WWER-1000 a comprehensive, passive-mode environmental protection system of decontamination of the radioactive steam-air mixture from the containment and the intercontainment area was suggested. This system includes the "wet" stage (scrubbers, etc.), the "dry" stage (sorption module), and also an ejector, which in a passive mode is capable of solving the multi-purpose task of decontamination of the air-steam mixture. For WWER-440/230 NPPs three protection levels: 1) a jet-vortex condenser; 2) the spray system; 3 ) a sorption module were suggested and installed. For modern designs of new generation NPPs, which do not provide for pressure release systems, a new passive filtering system together with the passive heat-removal system, which can be used during severe accidents in case all power supply units become unavailable, was proposed and after modernization was installed at the KudanKulam NPP (India).
\end{abstract}

\section{Keywords}

Nuclear Power Plants, Severe Accident, Environment Protection,

Radioactive Steam-Air Phase

\section{Introduction}

The safety of nuclear power plants (NPPs) is currently a problem of particular 
concern in all industrially developed countries throughout the world. The various science and technology projects being developed in this area seek to minimize the possibility of accidents. The world community has developed the general principles of providing NPP safety. Although these principles are universal for nuclear reactors of all types, they still need to be adapted to the design and operation peculiarities of specific reactors. These principles are being refined and supplemented on the basis of the operation experience and analysis of accidents at NPPs. Unfortunately, despite a whole range of preventive measures taken, accidents of various degrees of severity do happen. A large number of works study the possible consequences of accidents at NPPs. Some concern nuclear accidents involving only a partial damage of fuel elements or the loss a seal in the hot loop, accompanied by the breakthrough of noble gases and a small amount of volatile fission products, primarily, cesium and iodine [1]. Some focus on severe accidents leading to nuclear fuel destruction and melting of reactor core [2]-[7]. Although the probability of severe accidents is very low (less than $10^{-5}$ ), these accidents have very hazardous consequences and can lead to an extensive contamination of territory with radioactive compounds. To minimize the consequences of such accidents at NPPs, much attention is being given to operational safety issues. Particular emphasis has been placed on an in-depth protection, i.e., a multilevel protection. This involves the construction of a number of consecutive protective barriers: the fuel matrix ( $1^{\text {st }}$ barrier $)$, the shells of fuel elements $\left(2^{\text {nd }}\right.$ barrier), the reactor vessel ( $3^{\text {rd }}$ barrier) and protective shield ( $4^{\text {th }}$ barrier $)$.

During severe accidents, accompanied by either a partial or complete destruction of the reactor's active zone, the first three barriers are destroyed, and the main load is on the protective shield. At the same time the formation of large quantities of gaseous products, which leads to an abrupt increase in pressure inside the containment (protective casing) take place. Eventually, there is a risk of destroying the containment as such. Besides, such accidents may cause contamination of the nuclear power plant closed areas, such as the intercontainment area, technical and service corridors, reactor area, et cetera, due to leakage through non-airtight sectors of the containment. It was established that such a leak of the air-and-steam mix out of the containment can reach a rate of 0.3 to 1.0 per cent per $24 \mathrm{~h}$. Today, in order to prevent environmental pollution in the event of severe accidents, the operational nuclear power plants are equipped with emergency valves that can be activated to reduce the pressure inside the containment, in which case the air-and-steam flow, carrying radioactive aerosols and volatile fission products, is forced through special decontamination systems [5] [8] [9]. However, one of the drawbacks of such systems is that they cannot be used for a simultaneous decontamination of the steam-air mixture being let out of the containment and the air-and-steam mix inside the closed areas adjacent to the containment. Another disadvantage is that most existing decontamination systems are active systems, i.e. they need constant energy supply from outside sources during the accident. 
WWER-440/230 NPPs are first-generation Russian nuclear power stations that have been operated for more than 25 years now. As the engineering of the designs of these stations was realized long before severe accidents at Three Mile Island, Chernobyl and Fukushima Daiichi NPPs, all system of localization of accidents was plotted on the concept of impossibility of severe accidents at NPPS. However now point of view varies and the concept of improvement of a protection system of Russian WWER-440/230 NPPs with allowance for possibilities of severe accidents is now considered. All modifications of Russian WWER-440/230 NPPs belong to this first generation [10] [11] [12] [13].

Modern designs of new generation NPPs (EPR/Framatome ANP/, SWR-1000/ Framatome ANP/, AP-600 и AP-1000 /Westinghouse/, ESBWR /General Electric/, APWR /Mitsubishi/, ABWR /Toshiba and Hitachi/) do not provide for pressure-drop systems, assuming that the entire peak load will be withheld by the containment [14] [15] [16]. Calculations show that during $122 \mathrm{~h}$, pressure under the containment can raise up to $0.7 \mathrm{MPa}$, with the steam/air ratio being 2.7:1 [17]. This time is enough for the steam-air mass containing volatile radioactive fission products to penetrate $(0.3 \%$ to $3 \%$ a day) into the intercontainment area and then into the environment. To prevent radioactive contamination of the environment, modern designs propose using an active air decontamination system, which using high-capacity ventilators, will forward the air from the intercontainment area to filters filled with impregnated activated charcoal. This system requires regular electric power supply, which is a significant disadvantage of this technological approach.

The first part of this paper will be devoted to passive environmental protection system during severe accidents at NPPs, having two protective shells and pressure release system. The second part of the paper will be dedicated to some decisions on modernization of the Russian WWER-440/230 NPPs for localization of consequences of severe accidents. In the third part of the paper, a new passive filtering system for decontamination of intercontainment area during severe accidents at new generation NPPs will be described.

\section{A Technical Solution for Environmental Protection System at NPPs, Having Two Protective Shells and Pressure Release System}

For decreasing of environmental pollution in the event of severe accidents, the some NPPs are equipped with pressure release system that can be activated to reduce the pressure inside the containment. In this case the radioactive steam-air flow is passed through special decontamination set-ups. Some of them are shown in the Table 1 [8] [14] [15] [16]. Table 1 shows that the all systems, excepting sand bed and gravel filter have a high efficiency of localization of aerosols, and some of them have a high efficiency relative to molecular form of iodine. But these systems, excepting Germany system, including the filter based on molecular sieve, practically do not localize the organic form of iodine, such as methyl iodide. At the same time, all these systems also cannot be used for a 
Table 1. Survey and cost of venting systems [8] [14] [15] [16].

\begin{tabular}{|c|c|c|}
\hline Country & System & Decontamination factor (DF) \\
\hline China & Sand bed filter & 10 (aerosol) \\
\hline France & Sand bed filter & 10 (aerosol) \\
\hline France & Sand bed filter + iodine filter & $10($ aerosol $)+100$ (iodine $)$ \\
\hline Finland & $\begin{array}{l}\text { Venturi scrubber with } \\
\text { integrated metal fiber filter }\end{array}$ & $>10,000($ aerosol $)+100$ (iodine) \\
\hline $\begin{array}{l}\text { Germany } \\
\text { Germany }\end{array}$ & $\begin{array}{c}\text { Metal fiber filter }+ \text { molecular sieve iodine filter } \\
\text { Venturi scrubber with } \\
\text { integrated metal fiber filter }\end{array}$ & $\begin{array}{l}>10,000(\text { aerosol })+1000 \text { (iodine }) \\
>10,000(\text { aerosol })+100(\text { iodine })\end{array}$ \\
\hline Holland & $\begin{array}{l}\text { Venturi scrubber with } \\
\text { integrated metal fiber filter }\end{array}$ & $>10,000$ (aerosol) +100 (iodine) \\
\hline $\begin{array}{l}\text { Sweden } \\
\text { Sweden }\end{array}$ & $\begin{array}{l}\text { Column filled with gravel } \\
\text { Multi-venturi scrubber }+ \text { gravel moisture } \\
\text { separation system }\end{array}$ & $\begin{array}{c}100(\text { aerosol }) \\
1000(\text { aerosol })+1000 \text { (iodine) }\end{array}$ \\
\hline Switzerland & $\begin{array}{l}\text { SULZER scrubber with submerged } \\
\text { static mixing elements }\end{array}$ & $1000($ aerosol $)+1000$ (iodine) \\
\hline Switzerland & $\begin{array}{l}\text { Multi-venturi scrubber }+ \text { gravel moisture } \\
\text { separation system }\end{array}$ & $1000($ aerosol $)+1000$ (iodine $)$ \\
\hline Canada & Clearing system under vacuum & $10,000($ aerosol $)+1000$ (iodine $)$ \\
\hline
\end{tabular}

simultaneous decontamination of the steam-air mixture from the containment and the other closed areas of plants.

Based on fundamental investigations on localizing volatile fission products, a new design for a comprehensive, passive-mode environmental protection system, which can be used in the event of severe accidents, was suggested. Like most of the world's decontamination systems, design of this set-up has two stages of decontamination, including the condensation and sorption modules. However, unlike the known systems, proposed system has also an ejector, which in a passive mode is capable to solve the multi-purpose task of decontamination of the steam-air mixture.

Proposed system contains the following components: the pre-filter, the ejector, the condensation module, regenerative and air heat exchanger, and the sorption module.

In the event of an accident at operational nuclear power plants, having emergency pressure release valves, the air-and-steam mix (temperature: $423 \mathrm{~K}$, humidity: $100 \%$, pressure: 0.5 to $0.7 \mathrm{MPa}$ ) inside the containment would, after preliminary separation by the pre-filter from large grains, go the ejector whose suction nozzle is connected to the intercontainment area and/or other adjacent closed areas, and also to the steam generator's bypass lines. Inside the ejector, the gas flows from the containment and areas adjacent to the containment get mixed, with the temperature and pressure of the air-and-steam mix decreasing upon exiting the ejector (which results in some drop moisture-up to $15 \%$ of the total content of steam in the mix). After the ejector, the air-and-steam mix goes to the 
condensation module, where the steam is condensed and drop moisture is separated from the air-and-steam mix. At this stage, most of the steam is condensed and the air-and-steam mix is decontaminated from aerosols and inorganic forms of radioactive iodine at a degree of $95 \%$ to $97 \%$ as they are captured by the aqueous phase. Then the air-and-steam mix (temperature: from $343 \mathrm{~K}$ to $363 \mathrm{~K}$, humidity: 100\%), containing methyl iodide, residual quantities of aerosols, and inorganic forms of radioactive iodine, go to the sorption module. The sorbent ensures decontamination of the air-and-steam mix from methyl iodide (with decontamination factors being $10^{3}$ to $10^{4}$ ) and a final decontamination from radioactive aerosols and inorganic forms of iodine. As a result, the overall factor of decontaminating the air-and-steam mix from radioactive aerosols and all forms of radioactive iodine reaches $10^{4}$ to $10^{5}$ for the entire facility.

For NPPs at the stage of design, where an emergency pressure release system is not envisioned, proposed system includes simultaneous decontamination of the steam-air mixture coming from the intercontainment area and the bypass lines of the steam generator's pipe. Because it seems impossible to predict in advance the discharge of the air-and-steam mix through bypasses' leaky areas, the design for NPPs being developed, as in the case of operational ones, is planned with respect to a maximum possible radioactive discharge.

In this case, proposed design envisions that the ejector is connected to the intercontainment area and the specially designated silencer connected to the steam generator's bypass lines. Compressed air from the gas-holder (also included in the design), not the compressed air-and-steam mix inside the containment, will play the role of the driving force. All the remaining design components are the same as described above.

Finally, it is necessary noted that the proposed comprehensive decontamination system not only makes it possible to avoid emergency discharge of radioactive steam-air mixture into the environment under any accident scenario, but also would substantially contribute to the safety of both operational and planned nuclear power plants.

\section{Some Decisions on Modernization of the Russian WWER-440/230 Nuclear Power Plants for Localization of Consequences of Severe Accidents}

Unlike the NPPs, having two protective shells, the Russian WWER-440/230 NPPs have only one protective shell. This shell so-called containment or hermetic box capable to stand overpressure no more than $0.15 \mathrm{MPa}$. To avoid destruction of containment at overpressure more than $0.15 \mathrm{MPa}$, it is supplied with safety pressure release valves. At their operation during incident the steam-air mixture without cleaning gets in an environment. As at incident there is no destruction of a reactor active zone, penetration of a steam-air mixture without cleaning does not cause catastrophic consequences. In the event of a severe accident connected to break of pipelines of the first contour or destruction of the 
reactor vessel, pressure sharply rises inside containment and its destruction is possible. Unlike incident a consequences of a severe accident can be catastrophic. Therefore, now there is considered the concept of the modernization of the environmental protection system during severe accidents at a WWER-440/230 NPPs.

The considered concept assumes the following basic actions:

1) Increasing of a hermetic enclosure of containment for decreasing of leakages in technical corridors during severe accidents;

2) Installation of a jet-vortex condenser for dump of pressure in containment in a passive mode up to $0.02 \mathrm{MPa}$ during severe accident [18];

3) Modifying spray systems;

4) Installation of the safety filtering module for establishing a constant rarefaction of no lower than $20 \mathrm{~mm}$ water column inside the containment due to the organized removal of a radioactive steam-air mixture.

In accordance of this concept, the order of actions for localization of consequences of severe accidents will be the following.

In the event of a severe accident connected to sharp increase of pressure in containment, simultaneously with safety pressure release valves will work a jet-vortex condenser, which helps during $2-3 \mathrm{~min}$ in a passive mode to decrease a pressure inside containment up to $0.02 \mathrm{MPa}$. After that, a jet-vortex will continue its operation in a bubbler mode.

Through $1-2$ min after ending of the jet-vortex condenser operation the spray system will be activated. The use of spray system allows to carry out not only steam condensation inside containment and cooling of the reactor vessel, but also to carry out cleaning a steam-air mixture from radioactive fission products. For example, the use of a water solution of the hydrazine hydrate in this system will allow removing from containment atmosphere not only hydrophilic cesium radio aerosols and molecular form of iodine, but also partially methyl iodide.

In spite of the fact that spray system operation a pressure inside containment will be decreased, in a few hours after ending of spray system operation a pressure inside a containment will again raise due to heating of water solution, containing radioactive fusion products. Due to leakage through non-airtight sectors of the containment a radioactive steam-air mixture will penetrate in technical and services corridors of the plant and than from these areas to the environment. Despite the fact that the most part of activity will be located in containment after spray system operation, the penetration of the resting non-localize radioactive fission products to the environment can cause catastrophic consequences. To avoid this emergency penetration, it is planned to create a constant rarefaction inside the containment due to the organize evacuation of a steam-air mixture with cleaning on the special safety filtering module.

This safety filtering module (Figure 1) will contain the granular sorbents "Fizkhimin" developed in IPCE RAS, and the filtering materials developed in 


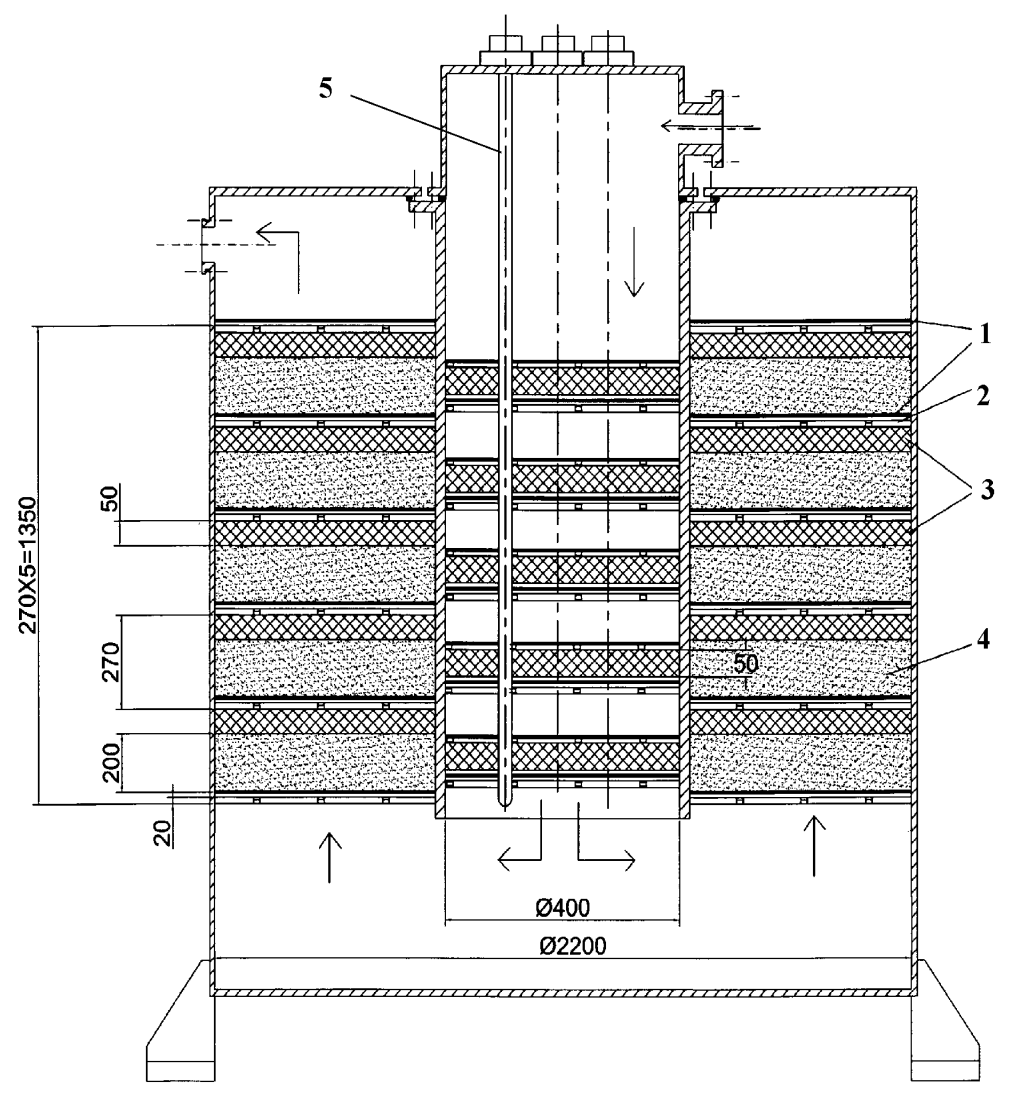

Figure 1. Safety filtering module (1-metal gauze, 2-separating lattice, 3-filtering materials developed in IPPE, 4-sorbent "Fizkhimin" developed in IPCE RAS, 5-thermo-electric heater).

IPPE. The developed safety filtering module allows to carry out clearing of steam-air mixture from radioactive aerosols and all volatile compounds of radioiodine more than 99.95 per cents.

Finally, it is necessary noted that the proposed decisions of the modernization of environmental protection system during severe accidents at the Russian WWER-440/230 NPPs makes possible not only to avoid emergency penetration of radioactive steam-air mixture into the environment during severe accidents, but also to continue safety operation of these plants in future.

\section{A Passive Filtering System for Decontamination of Intercontainment Area during Severe Accidents at New Generation NPPs}

To prevent radioactive contamination of the environment from intercontainment area, modern designs of new generation NPPs (EPR /Framatome ANP/, SWR-1000/Framatome ANP/, AP-600 и AP-1000 /Westinghouse/, ESBWR/General Electric/, APWR /Mitsubishi/, ABWR /Toshiba and Hitachi/) provide for using venting filtering systems, which require regular electric power supply. These systems are an active decontamination set-up.

In accordance with the general requirements for safety systems, alongside ac- 
tive ventilation systems for intercontainment space, NPPs should include a passive ventilation system, which can be used during severe accident with a complete loss of power supply.

Based on fundamental research of localization of volatile fission products, a new design for a passive-mode environmental protection system, which can be used in the event of severe accidents, was proposed (Figure 2) [19]. The main purpose of this passive filtration system is to maintain safe pressure inside the intercontainment area by means of passive organized evacuation of the radioactive steam-air mixture coming from the containment during accidents with total loss of all power supply.

The proposed system includes two major components: a passive heat-removal system (PHRS), which was developed in VNIIAM, and sorption module, which was developed in IPPE, VNIIAM and AEP.

The passive heat-removal system (PHRS) is designed to withdraw heat from the steam generator during accidents with a complete loss of power supply [19]. One of these system's tracts consists of an air heat exchanger, a draft tube, and two gates. The entire PHRS includes 12 or more such tracts, which meet at a deflector located in the upper part of the containment. During normal operation of NPP, this system is virtually idle. Although because of some minor leakages in the shutters of the gates some part of the heat from the piping of the steam generator is continuously withdrawn to the gas phase coming to the deflector. Therefore, in the waiting mode the sorption module located inside the deflector will always have a temperature above $523 \mathrm{~K}$.

In case of a severe accident, the steam-supply pipes of the second loop and the feed water pipes automatically close. Steam from the steam generator is forwarded to the heat exchanger of PHRS, simultaneously causing the shutters of

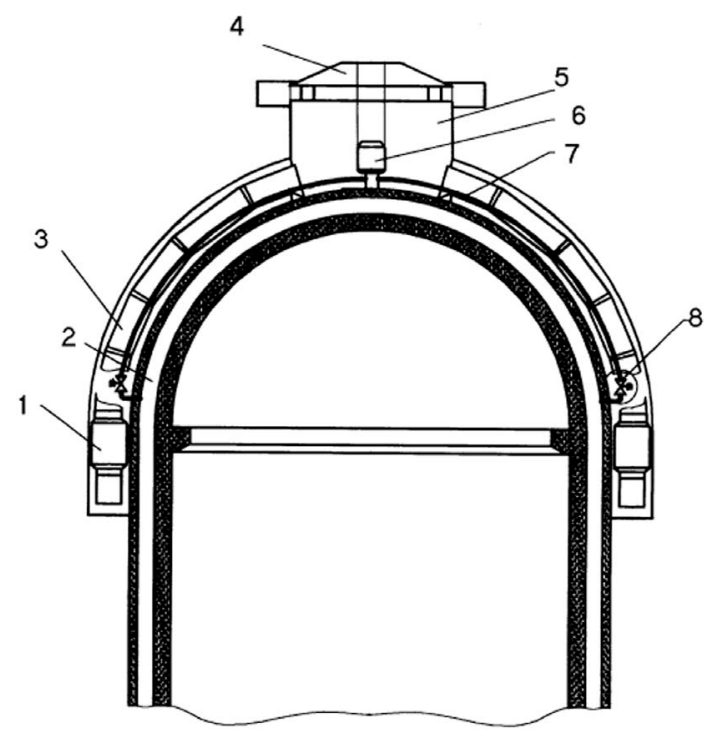

Figure 2. The layout of the PFS for decontamination of intercontainment area (1-heat-exchanger of the PHRS, 2-intercontainment area, 3-pipe of the PHRS, 4-deflector, 5-collector of the PHRS, 6-filtering unit, 7-piping, 8-valve with pneumatic drive). 
the gates to open. The ambient air begins to pass through the air heat exchangers and a passive heat removal starts. Note that the higher the pressure in the steam generator is, the wider the shutters of the gates open thereby allowing more heat to be withdrawn from the steam generator.

At the same time, depression in the intercontainment area is provided using passive-filtration system (PFS) tracts installed in the pipe of PHRS. The upper part of the tract is located in the zone with a temperature above $523 \mathrm{~K}$, whereas the lower part of the tract has a temperature of about $323 \mathrm{~K}$. The temperature difference of the gas media at the beginning and end of the tract produces a natural draft of gas phase in the tract of PFS. The radioactive steam-air mixture evacuated from the intercontainment space is passed through a special filtering unit, which is situated at the upper point of the external protective shell inside the deflector.

The filtering unit should meet the following requirements:

1) The pressure differential on the filtering unit should not be larger than 20 $\mathrm{Pa}$ at a temperature of $293 \mathrm{~K}$ and pressure of $0.1 \mathrm{MPa}$ for a nominal linear gas flow rate through the filtering unit of at least $1.6 \mathrm{~cm} / \mathrm{sec}$;

2) The filtering unit should preserve its filtration and sorption properties in a temperature range from $293 \mathrm{~K}$ to $573 \mathrm{~K}$ and at a steam content of the steam-air mixture of up to $30 \mathrm{vol} \%$;

3) Under above-mentioned conditions, efficiency of decontamination of the steam-air mixture from both radioactive aerosols and molecular iodine should be higher than $99.9 \%$ and from organic iodine compounds should be higher than 99.0\%;

4) The desorption of radioactive iodine should not be higher than $0.1 \%$ of the total mass of compounds localized in the module during the heat-up of the module up to $573 \mathrm{~K}$.

As a result of preliminary study, a basic concept of the filtering unit was developed. The filtering unit will be made of required number of identical units, the design parameters of which are presented in Table 2. The unit has two stages for radioactive steam-air mixture decontamination. The aerosol stage containing filtering material developed in IPPE is designed to remove radioactive aerosols with an efficiency of not less than $99.9 \%$. The sorption stage containing granulated sorbents "Fizkhimin" developed in IPCE RAS is to remove volatile radioactive iodine compounds, including methyl iodide, with an efficiency of not less than $99.9 \%$.

Finally, it is necessary noted that the proposed passive filtering system together with the passive heat-removal system would make it possible to not only avoid penetration of radioactive steam-air mixture into the environment during severe accidents at new generation NPPs, but also raise their safety level. This system was developed for the KudanKulam NPP (India) [19]. Now this system after modernization by Russian companies "Krasnaya Zvezda" and "Progress-Ekologiya" was installed at the $1^{\text {st }}$ unit of KudanKulam NPP. 
Table 2. Design parameters of sorption and aerosol stages of passive filtering unit.

\begin{tabular}{|c|c|}
\hline \multicolumn{2}{|l|}{ Sorption stage } \\
\hline Working temperature, $\mathrm{K}$ & $293-575$ \\
\hline Open flow area, $\mathrm{cm}^{2}$ & 460 \\
\hline Pressure difference in the nominal air flow (air temperature $293 \mathrm{~K}$ ), Pa & 6.9 \\
\hline $\begin{array}{l}\text { Pressure difference in the nominal air flow } \\
\text { (air temperature } 575 \mathrm{~K} \text {; steam content } 20.4 \text { vol\%), Pa }\end{array}$ & 20.6 \\
\hline Air decontamination efficiency for molecular iodide, $\%$ & $\geq 99.9$ \\
\hline Air decontamination efficiency for organic iodine compounds (methyl iodide), \% & $\geq 99.9$ \\
\hline \multicolumn{2}{|l|}{ Aerosol stage } \\
\hline Working temperature range, $\mathrm{K}$ & $293-575$ \\
\hline Active filtering area, $\mathrm{m}^{2}$ & 0.73 \\
\hline Pressure difference in the nominal air flow (air temperature $293 \mathrm{~K}$ ), $\mathrm{Pa}$ & 3.2 \\
\hline $\begin{array}{l}\text { Pressure difference in the nominal air flow } \\
\text { (air temperature } 575 \mathrm{~K} \text {; steam content } 20.4 \text { vol\%), } \mathrm{Pa}\end{array}$ & 9.6 \\
\hline Air decontamination efficiency for aerosols, $\%$ & $\geq 99.9$ \\
\hline Dust capacity for aerosols with a modal particle diameter of $0.5 \mu \mathrm{m}, \mathrm{g}$ & 40 \\
\hline
\end{tabular}

\section{Conclusion}

In conclusion it is necessary noted that the proposed decisions of the modernization of environmental protection systems during severe accidents at the different types of NPPs makes possible not only to avoid emergency penetration of radioactive steam-air mixture into the environment during severe accidents, but also to continue safety operation of NPPs in future.

\section{References}

[1] Kastchiev, G., Kromp, W., Kurth, S., Lochbaum, D., Lyman, E., Sailer, M. and Schneider, M. (2007) An Account of Events in Nuclear Power Plants Since the Chernobyl Accident in 1986. The Greens/European Free Alliance, Brussels.

[2] Nuclear Fuel Behaviour in Loss-of-Coolant Accident (LOCA) Conditions (2009) Report NEA/CSNI R15. OECD, Paris.

[3] Hydrogen and Fission Product Issues Relevant for Containment Safety Assessment under Severe Accident Conditions (2010) Report NEA/CSNI R3. OECD, Paris.

[4] ISP-49 on Hydrogen Combustion (2011) Report NEA/CSNI R9. OECD, Paris.

[5] Status Report on Hydrogen Management and Related Computer Codes (2014) Report NEA/CSNI R8. OECD, Paris.

[6] Status Report on Spent Fuel Pools under Loss-of-Cooling and Loss-of-Coolant Accident Conditions (2015) Final Report NEA/CSNI R2. OECD, Paris.

[7] Schwantes, J.M., Orton, C.R. and Clark, R.A. (2012) Analysis of a Nuclear Accident: Fission and Activation Product Releases from the Fukushima Daiichi Nuclear Facility as Remote Indicators of Source Identification, Extent of Release, and State of Damaged Spent Nuclear Fuel. Environmental Science \& Technology, 46, 8621-8627. https://doi.org/10.1021/es300556m 
[8] Status Report on Filtered Containment Venting (2014) Report NEA/CSNI R7. OECD, Paris.

[9] Topf, C., Sempere-Belda, L., Fischer, M., Tscheschlok, K. and Volkmann, C. (2013) Full System Decontamination at German Nuclear Power Plant Unterweser. International Journal for Nuclear Power, 58, 216-220.

[10] Performance Analysis of WWER-440/230 Nuclear Power Plants (1997) Report IAEA-TECDOC-922. IAEA, Vienna.

[11] Slugen, V. (2011) Safety of VVER-440 Reactors: Barriers against Fission Products Release. Springer-Verlag London Limited, London.

https://doi.org/10.1007/978-1-84996-420-3

[12] Safety Analysis of WWER-440 Nuclear Power Plants: Potential Consequences of a Large Primary to Secondary System Leakage Accident (2009) Report IAEA-TECDOC-1610. IAEA, Vienna.

[13] Lillington, J.N. (2004) Future of Nuclear Power. Elsevier Ltd., Amsterdam.

[14] Status of Advanced Light Water Reactor Designs (2004) Report IAEA-TECDOC-1391. IAEA, Vienna.

[15] Pioro, I. (2016) Handbook of Generation IV Nuclear Reactors. Elsevier, Amsterdam.

[16] Schulz, T.L. (2006) Westinghouse AP1000 Advanced Passive Plant. Nuclear Engineering and Design, 236, 1547-1557. https://doi.org/10.1016/j.nucengdes.2006.03.049

[17] Dillman, H.G. and Bunz, H. (1991) Design of a Filter System for PWR Containment Venting. J. Aeros. Sci., 22, S701-S704. https://doi.org/10.1016/S0021-8502(05)80197-1

[18] Condensing-Cleaning Device for Aerosols and Volatile Form of Iodine (1995) Promotion Materials, Inter. Exibit. “Nuctek'95”, Moscow, Russia.

[19] Agrawal, S.K., Chauhan, A. and Mishra, A. (2006) The VVERs at KudanKulam. Nuclear Engineering and Design, 236, 812-835.

https://doi.org/10.1016/j.nucengdes.2005.09.030 